\title{
L1 is associated with micrometastatic spread and poor outcome in colorectal cancer
}

\author{
Jussuf T Kaifi ${ }^{1}$, Uta Reichelt ${ }^{2}$, Alexander Quaas ${ }^{2}$, Paulus G Schurr ${ }^{1}$, Robin Wachowiak ${ }^{1}$, \\ Emre F Yekebas ${ }^{1}$, Tim Strate ${ }^{1}$, Claus Schneider ${ }^{1}$, Klaus Pantel ${ }^{3}$, Melitta Schachner ${ }^{4}$, \\ Guido Sauter ${ }^{2}$ and Jakob R Izbicki ${ }^{1}$ \\ ${ }^{1}$ Department of General, Visceral and Thoracic Surgery, University Medical Center Hamburg-Eppendorf, \\ Hamburg, Germany; ${ }^{2}$ Institute for Pathology, University Medical Center Hamburg-Eppendorf, Hamburg, \\ Germany; ${ }^{3}$ Institute for Tumor Biology, University Medical Center Hamburg-Eppendorf, Hamburg, Germany \\ and ${ }^{4}$ Institute for Neuronal Biosynthesis, Center for Molecular Neurobiology, University Medical Center \\ Hamburg-Eppendorf, Hamburg, Germany
}

\begin{abstract}
L1 is a cell adhesion molecule expressed at the invasive front of colorectal tumors with an important role in metastasis. The aim of the present study was to determine L1 protein expression in a large cohort of colorectal cancer patients and its impact on early metastatic spread and survival. A total of 375 patients that underwent surgical treatment for colorectal cancer were chosen retrospectively. A tissue microarray was constructed of 576 tissue samples from these patients and analyzed by immunohistochemistry with a monoclonal antibody against human L1 (UJ127). Lymph node and bone marrow micrometastasis were assessed with monoclonal antibodies Ber-EP4 and pancytokeratin A45-B/B3, respectively. Associations between L1 expression and lymph node, bone marrow micrometastasis and survival were investigated with Fisher's, log-rank test and Cox multivariate analysis. All statistical tests were two-sided. L1 was detected in a subset of 48 (13\%) of 375 patients examined. Analysis of L1 expression and survival revealed a significantly worse outcome for L1-positive patients by log-rank test $(P<0.05)$. Multivariate Cox regression analysis showed the strongest independent prognostic impact of $L 1$ expression $(P<0.05)$. Fisher's test revealed a significant association of $L 1$ expression and presence of disseminated tumor cells in lymph nodes and bone marrow $(P<0.05)$. L1 is a powerful prognostic marker for patients that undergo complete surgical resection. It may have a role in early metastatic spread, as L1 is associated with micrometastases to both the lymph nodes and bone marrow. Thus, L1 should be explored further as a target for adjuvant therapy for micrometastatic disease.

Modern Pathology (2007) 20, 1183-1190; doi:10.1038/modpathol.3800955; published online 14 September 2007
\end{abstract}

Keywords: colorectal cancer; L1 cell adhesion molecule; micrometastasis

The neural cell adhesion molecule L1 (CD171) has been shown to be expressed at the invasive front of colorectal cancer cells and is associated with tumor progression. ${ }^{1,2} \mathrm{~L} 1$, a $200-220 \mathrm{kDa}$ type I glycoprotein of the immunoglobulin superfamily, plays a role in development of the nervous system by regulating cell interactions, including neuronal migration, neurite outgrowth and fasciculation, neuronal survival and synaptic plasticity. ${ }^{3-6}$ L1 may interact with a variety of different molecules including itself. ${ }^{7}$ Besides homophilic binding, L1 undergoes also heterophilic interactions, for example, with integ-

Correspondence: Dr JT Kaifi, MD, Department of General, Visceral and Thoracic Surgery, University Medical Center HamburgEppendorf, Martinistrasse 52, Hamburg 20246, Germany.

E-mail: jkaifi@uke.uni-hamburg.de

Received 13 May 2007; revised 07 August 2007; accepted 09

August 2007; published online 14 September 2007 rins. ${ }^{8}$ L1 is detected on a variety of tumor cells of neuronal, mesothelial and epithelial origin, such as of neuroblastomas, melanomas, lymphomas, small cell lung, colon and breast cancers. ${ }^{9-15}$ After cleavage by a metalloproteinase (ADAM10), from the tumor cell surface L1 is released into the serum, for instance of cancer patients. ${ }^{5,16-19}$ Its presence in tumor and serum has a prognostic significance in ovarian, uterine and renal cell carcinomas and is associated with metastasis of melanomas. ${ }^{15,20,21}$

Metastasis involves several sequential steps and is a highly organized process. Early metastatic relapse after complete resection of an apparently localized tumor indicates that disseminated tumor cells or micrometastases, undetectable by current routine methods, may have been present at the time of surgery. ${ }^{22}$ Tumor cells disseminate to regional lymph nodes and home to secondary organs, in which they may reside as viable cells in a dormant 
state. Some of these cells may eventually become precursors of metastases arising many years after curative resection of the primary tumor. ${ }^{22}$ Current tumor staging procedures are unable to detect single disseminated tumor cells, and sensitive methods have, therefore, been developed to detect disseminated tumor cells in lymph nodes and distant organs, in particular bone marrow. ${ }^{22,23}$ The presence of micrometastatic tumor cells in histopathologically tumor-free lymph nodes is a strong prognostic factor for colon cancer. ${ }^{24-26}$ The presence tumor cells in bone marrow has to be taken as evidence of the general disseminative capability of an individual tumor. ${ }^{27}$ Such dissemination is a predictor for the postoperative occurrence of overt metastasis at distant sites, although the skeleton is not a preferred site of recurrence in colorectal cancer.

The aim of our study was to evaluate whether L1 is associated with micrometastatic spread and could serve as a potential prognostic factor of colorectal cancer patients.

\section{Materials and methods}

\section{Patients and Samples}

This study was approved by the Ethics Committee of the Chamber of Physicians in Hamburg, Germany. Written informed consent was obtained from all patients for use of the resected samples. For this study, 576 specimens of 375 patients with colorectal cancer who underwent surgery in the Department of Surgery at University Medical Center HamburgEppendorf between January 1991 and February 2005 were chosen retrospectively. Out of these, 375 primary tumors, 128 lymph node metastases, 48 liver metastases and 25 local relapse samples were used to construct a tissue microarray. Tumor stage and grade were classified according to the tumornode-metastasis classification of the International Union Against Cancer. ${ }^{28}$ All clinical and histopathological data including sex, tumor size, lymph node metastasis, tumor type and disease stage were obtained from the clinical and pathological records.

\section{Tissue Microarray Construction}

Tissue samples were fixed in $4 \%$ buffered formalin, paraffin embedded and used for tissue microarray construction as described. ${ }^{29}$ Hematoxylin-eosin stained sections were made from selected primary tumor blocks (donor blocks) to define representative tumor regions. Tissue cylinders $(0.6 \mathrm{~mm}$ in diameter) were then punched from that region of the donor block using a homemade semiautomated tissue arrayer. The punch biopsies were obtained from a peripheral or central area with high number of vital tumor cells and little necrosis. Control samples included normal esophagus mucosa $(n=10)$, endometrium $(n=2)$, skin $(n=2)$, skeletal muscle $(n=2)$, heart muscle $(n=2)$, colon mucosa $(n=2)$, lung $(n=2)$, lymph node $(n=2)$, prostate $(n=2)$ and kidney $(n=2)$. An overview of a complete tissue microarray is shown in Figure 1a; single tissue spots of adenocarcinomas and lymph node metastases are shown in Figure 1b. Threemicrometer sections were made by use of the Paraffin Sectioning Aid System (Instrumentics, Hackensack, NJ, USA).

\section{Immunohistochemical Staining of L1 and Evaluation of Expression}

Heat-induced autoclave antigen retrieval was performed at $120^{\circ} \mathrm{C}$ for $5 \mathrm{~min}$ with TEC (pH 7.8). Peroxidase blocking $\left(3 \% \mathrm{H}_{2} \mathrm{O}_{2}\right.$ in methanol) was performed for $10 \mathrm{~min}$. Incubation with the prediluted primary antibody was for $2 \mathrm{~h}$ at $30^{\circ} \mathrm{C}$ using a monoclonal murine anti-human monoclonal antibody (IgG 1 , 1:150; clone UJ127, NeoMarkers, Fremont, CA, USA) binding to the extracellular domain of the transmembrane L1 protein. Visualization of the immunoreaction was performed with DABchromogen/EnVision Polymer-HPR (Dako K3468 and K4001). A mild counterstaining was performed with hematoxylin for $30 \mathrm{~s}$. In tumors, the staining intensity was scored in a four-step scale $(0,1+, 2+$, $3+$ ) by one pathologist (UT). In addition, the percentage of positive cells was estimated. The results for L1 in tissue microarrays were then grouped into three categories including negative (no staining at all), weak $(1+$ staining or $2+$ staining in $<30 \%$ of tumor cells) and strong $(2+$ staining in more than $30 \%$ of cells or $3+$ staining). In normal tissues, the staining results were described separately for each distinguishable cell type $(0,1+, 2+, 3+)$.

\section{Detection of Tumor Cells in Bone Marrow and Lymph Nodes}

Bone marrow aspirates of $4-8 \mathrm{ml}$ were obtained from the iliac crest of patients on the day of surgery and processed as described previously. ${ }^{30-32}$ Briefly, the aspirates were collected in heparin, and mononuclear cells were isolated by density-gradient centrifugation through Ficoll-Hypaque (Pharmacia, Freiburg, Germany) at $400 \mathrm{~g}$ for $30 \mathrm{~min}$. Cells were then subjected to cytocentrifugation at $150 \mathrm{~g}$ for $3 \mathrm{~min}$ at room temperature, so that cells could attach to a glass slide. To visualize tumor cells in bone marrow, we used monoclonal antibody A45-B/B3 ( $\mathrm{IgG}_{1}$; Micromet, Munich, Germany) directed against an epitope on various cytokeratins, including cytokeratin 8, 18 and 19. Non-immune $\operatorname{IgG}_{1}$ was used as a control antibody. Visualization was performed by the APAAP technique described above. Counterstaining was performed with Mayer's hematoxylin. We used the Automated Cellular Imaging System (ACIS, ChromaVision, Medical Systems Inc., San 
a

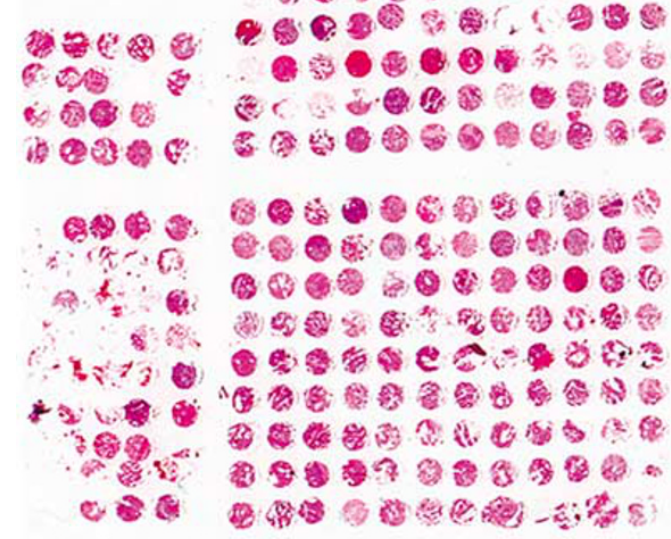

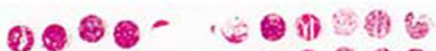

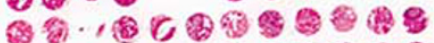

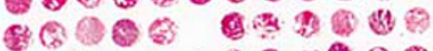

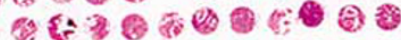

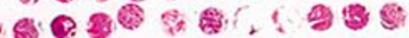

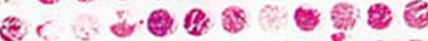

\section{st} \\ ,

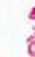

\section{,}

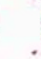

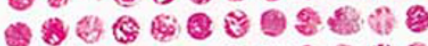

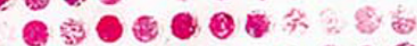

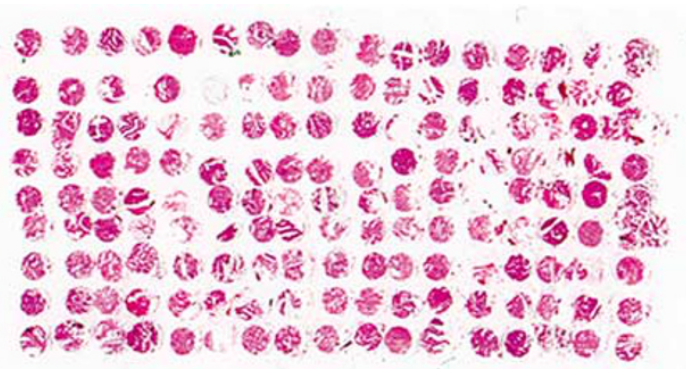
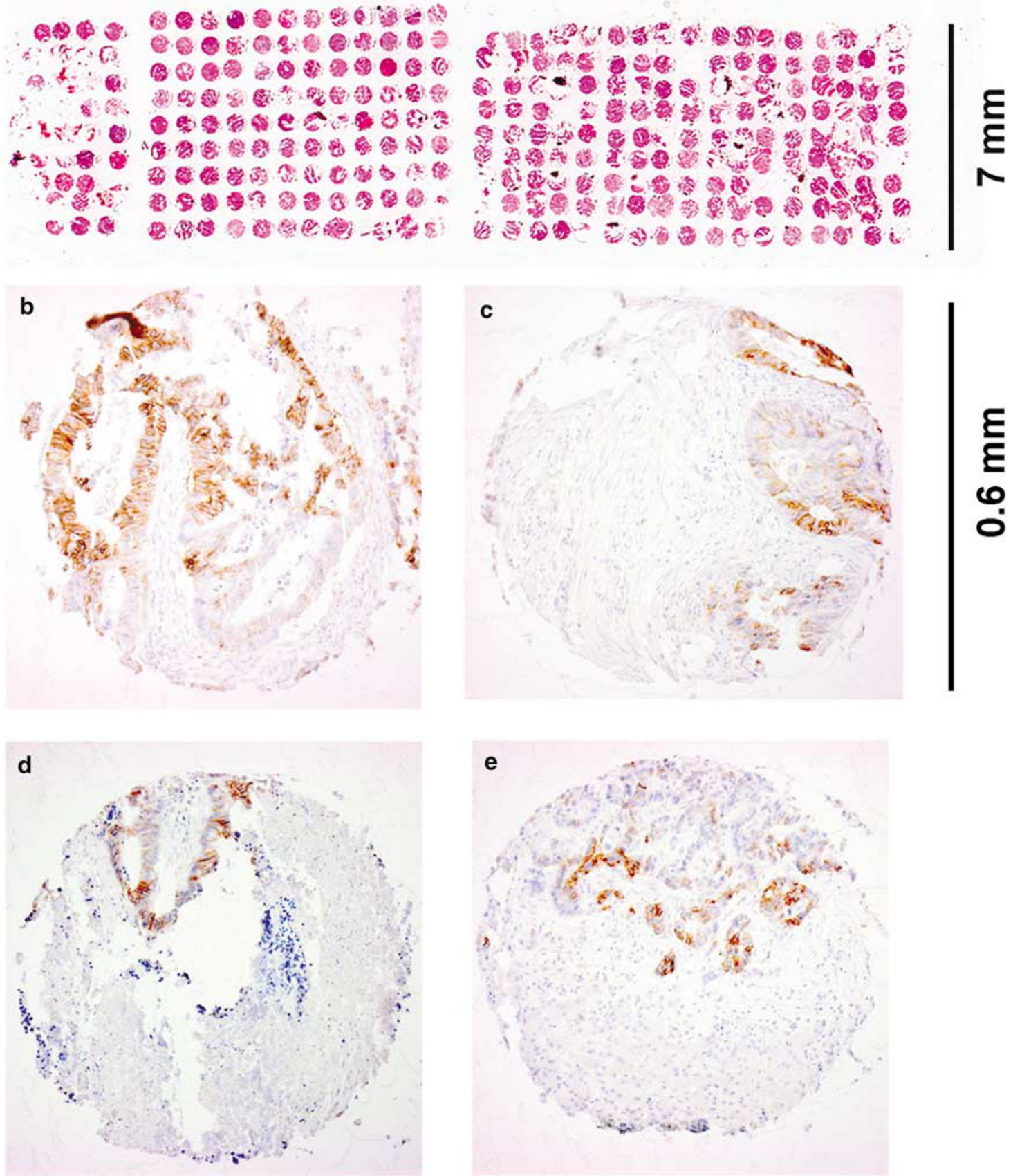

Figure 1 Colorectal cancer tissue microarray. (a) Complete colorectal cancer tissue microarray, stained with hematoxylin-eosin, consisting of one paraffin block $(25 \times 30 \mathrm{~mm}$ ). (b and c) Examples of a single L1-immunostained tissue spots of primary colon adenocarcinomas (magnification $\times 100$ ). (d and $\mathbf{e}$ ) Examples of single tissue spot of colon adenocarcinoma lymph node metastases with L1-positive immunostaining (magnification $\times 100$ ). Immunohistochemical staining was performed by the peroxidase method using a monoclonal antibody against human L1. 
Juan Capistrano, CA, USA) to screen immunostained bone marrow slides for disseminated tumor cells. ${ }^{33}$

Lymph nodes were systematically sampled during lymphadenectomy as described previously. ${ }^{31}$ Each lymph node that was removed at the time of surgery was divided into two parts. One part was embedded in paraffin for routine histopathological staging and stained with hematoxylin and eosin; the other part was snap-frozen in liquid nitrogen. Lymph nodes from patients without evidence of nodal metastasis on routine histopathological examination were screened for the presence of epithelial tumor cells with the Ber-EP4 monoclonal antibody ( $\operatorname{IgG}_{1}$; Dako), as described previously. ${ }^{31}$ This antibody is directed against an epithelial cell adhesion molecule on the surface and in the cytoplasm of nearly all epithelial cells, and it does not react with mesenchymal tissue, including lymphoid tissue. ${ }^{34}$ Two cryostat sections (5-6 $\mu \mathrm{m}$ thick) were cut at three different levels in each lymph node. Sections were stained by the APAAP technique. Normal esophageal mucosa served as the positive staining control. The slides stained with hematoxylin and eosin or the immunostained sections were evaluated in a blinded manner. Minimal tumor cell involvement in a lymph node that was considered to be tumor-free by routine histopathological staining was defined as having 1-10 Ber-EP4-positive cells in the body of the lymph node.

\section{Survival Data}

Clinical follow-up data were obtained by reviewing the hospital records, direct communication with the attending physicians and from the Cancer Registry of Hamburg. Survival data were available from 247 patients of whom primary tumors were also examined for L1. Histopathological examination of the surgical specimen showed that the resected margins were tumor free. No evidence of distant metastasis was found for any patient included for survival analysis at the time of surgery. Tumor-specific survival was calculated from the date of surgical excision of the primary tumor to the date of death or last follow-up. Patients who died from causes other than colorectal cancer were censored at the time of death. Patients whose death was clearly documented as attributable to colorectal cancer were considered to have died of that disease. Other deaths were not considered to have been caused by colorectal cancer.

\section{Statistical Analysis}

SPSS $^{\circledR}$ for Windows (version 11.5.1) (SPSS Inc., Chicago, IL, USA) was used for statistical analysis. Cross table statistics were performed with Fisher's test. Survival curves were plotted using the KaplanMeier method and analyzed using the log-rank test.
To simultaneously assess the independent association of L1 expression and colorectal carcinoma outcome with covariates that were statistically significantly associated with tumor-specific and overall survival in univariate analysis, such as tumor invasion depth, lymph node metastasis and histologic grading, Cox regression analysis was performed for multivariate analysis. Significance statements refer to $P$-values of two-tailed tests that were less than 0.05 .

\section{Results}

Characteristics of the Patients and L1 Expression in Colorectal Cancer

A total of 576 tissue samples from 375 retrospectively chosen colorectal cancer patients were included in our study and examined immunohistochemically on a tissue microarray. A total of 375 primary tumors, 128 lymph node metastases, 48 liver metastases and 25 local relapse samples were used to construct a tissue microarray. Patients' characteristics and L1 expression, correlated with age, sex, localization of the primary tumor, histological grading, tumor invasion depth, lymph node status and presence of metastases are listed in Table 1. Briefly, the median age of patients was 65 years. Of all samples included in this study, $48(13 \%)$ of 375 patients had L1-positive tumor samples (Table 1). Figure 1a represents a tissue microarray, and Figure $1 \mathrm{~b}$ shows representative staining patterns of tissue spots for L1 of primary colorectal adenocarcinomas and lymph node metastases.

\section{L1 Expression and Survival}

Follow-up data of patients whose primary colorectal cancer was surgically completely resected (R0) and that did not present with distant metastasis (M0) at surgery were available in 247 cases. Only patients whose primary colorectal tumor was analyzed for L1 expression on the tissue microarray were included for survival analysis. Median follow-up time of all 247 patients included for survival analysis was 46 months. The median follow-up time of survivors $(n=165)$ was 54 months, of L1-positive patients $(n=48) 28$ months and of L1-negative patients $(n=199) 48$ months. Survival was analyzed by the Kaplan-Meier method, and the log-rank test was used for univariate analysis. Overall survival and tumor-specific survival among patients with L1positive tumors compared with patients with L1-negative tumors are shown in Figure 2. L1 expression in the primary tumor was statistically significantly associated with poorer overall and tumor-specific survival than no L1 expression $(P<0.001$ by log-rank test). Five-year overall survival associated with L1-positive tumors was $47 \%$ 
(95\% CI: 31-63\%), and the five-year overall survival associated with L1-negative tumors was $69 \%(95 \%$ CI: $62-76 \%)$. The five-year tumor-specific survival

Table 1 Clinicopathologic features of colorectal cancer patients and L1 expression in this study

\begin{tabular}{|c|c|c|c|}
\hline Variable & Total & L1 negative & L1 positive \\
\hline Total & 375 & $327(87 \%)$ & $48(13 \%)$ \\
\hline \multicolumn{4}{|l|}{ Age (years) } \\
\hline$<60$ & $122(33 \%)$ & $102(27 \%)$ & $20(5 \%)$ \\
\hline$>60$ & $253(67 \%)$ & $225(60 \%)$ & $28(8 \%)$ \\
\hline \multicolumn{4}{|l|}{ Sex } \\
\hline Male & $224(60 \%)$ & $191(51 \%)$ & $33(9 \%)$ \\
\hline Female & $151(40 \%)$ & $136(36 \%)$ & $15(4 \%)$ \\
\hline \multicolumn{4}{|l|}{ Localization } \\
\hline Ascending colon & $72(19 \%)$ & $63(17 \%)$ & $9(3 \%)$ \\
\hline Transverse colon & $23(6 \%)$ & $21(6 \%)$ & $2(1 \%)$ \\
\hline Descending colon & $7(2 \%)$ & $5(1 \%)$ & $2(1 \%)$ \\
\hline Sigmoid colon & $85(23 \%)$ & $73(20 \%)$ & $12(3 \%)$ \\
\hline Rectum & $188(50 \%)$ & $165(44 \%)$ & $23(6 \%)$ \\
\hline \multicolumn{4}{|l|}{ Histological grading } \\
\hline G1 & $4(1 \%)$ & $4(1 \%)$ & 0 \\
\hline G2 & $307(82 \%)$ & $266(71 \%)$ & $41(11 \%)$ \\
\hline G3 & $64(17 \%)$ & $57(15 \%)$ & $7(2 \%)$ \\
\hline \multicolumn{4}{|l|}{ Tumor depth } \\
\hline pT1 & $18(5 \%)$ & $16(4 \%)$ & $2(1 \%)$ \\
\hline pT2 & $79(21 \%)$ & $71(19 \%)$ & $8(2 \%)$ \\
\hline pT3 & $235(63 \%)$ & $201(54 \%)$ & $34(9 \%)$ \\
\hline pT4 & $43(12 \%)$ & $39(10 \%)$ & $4(1 \%)$ \\
\hline \multicolumn{4}{|l|}{ Lymph nodes } \\
\hline pNo & $187(50 \%)$ & $168(45 \%)$ & $19(5 \%)$ \\
\hline pN1 & $89(24 \%)$ & $74(20 \%)$ & $15(4 \%)$ \\
\hline $\mathrm{pN} 2$ & $99(26 \%)$ & $85(23 \%)$ & $14(4 \%)$ \\
\hline \multicolumn{4}{|l|}{ Metastasis } \\
\hline M0 & $289(77 \%)$ & $241(64 \%)$ & $48(13 \%)$ \\
\hline M1 & $86(23 \%)$ & $86(23 \%)$ & 0 \\
\hline
\end{tabular}

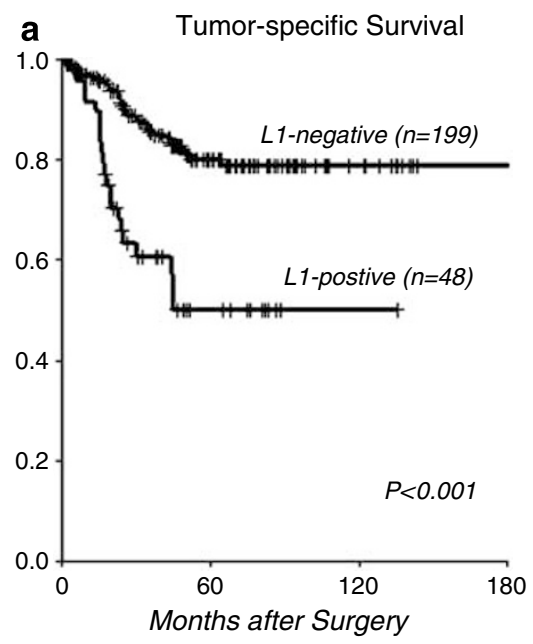

associated with L1-positive patients was 50\% (95\% CI: $34-66 \%$ ) and with L1-negative patients $80 \%$ (95\% CI: 68-92\%).

\section{L1 as an Independent Prognostic Factor}

A Cox regression model for multivariate analysis was applied to examine whether various factors were associated with reduced overall and tumorspecific survival (Table 3). The following covariates that were statistically significantly associated with reduced survival of patients by univariate analysis by log-rank test were included in the model as potential risk factors: tumor invasion depth (pT1-4), lymph node status (pNo-2), grading (G1-3) and L1 expression. We found that survival was independently associated with L1 expression, lymph node metastasis status and tumor invasion depth by multivariate analysis. L1 expression was more strongly associated with worse outcome (overall survival: $\quad P=0.025$; tumor-specific survival: $P=0.001$ ) than was presence of lymph node metastasis (overall survival: $P=0.007$; tumor-specific survival: $P=0.007)$ and tumor invasion depth (overall survival: $P=0.006$; tumor-specific survival: $P=0.001$ ) (Table 2).

\section{L1 Expression and Lymph Node and Bone Marrow Micrometastasis}

Mononuclear cells, isolated from bone marrow aspirates, were obtained from the iliac crest of patients on the day of surgery and analyzed for the presence of tumor cells with the pancytokeratin A45-B/B3 monoclonal antibody. Tumor cells were detected in $18(22 \%)$ of 82 bone marrow aspirates of colorectal cancer patients. Bone marrow micrometastasis was strongly and negatively associated with

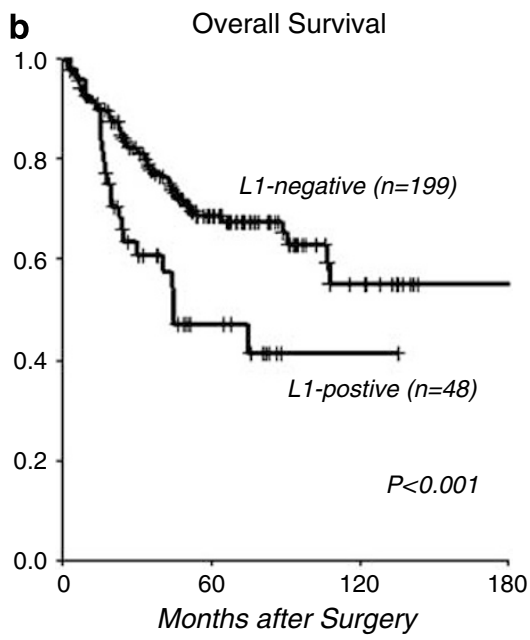

Figure 2 Kaplan-Meier survival curves for tumor-specific (a) and overall (b) survival and L1 expression in primary tumors of completely resected colorectal adenocarcinoma patients. Patients who did not present with metastases (M0) at initial diagnosis and whose primary tumors were surgically and histopathologically completely resected (R0) were included for survival analysis $(n=247)$. $P$-values were calculated with log-rank test. 
Table 2 Multivariate Cox regression analysis for overall and tumor-specific survival

\begin{tabular}{lcc}
\hline & $R R / 95 \%$ CI & P-values \\
\hline Overall survival & & \\
Tumor invasion depth pT1-4 & $1.736(1.174-2.568)$ & 0.006 \\
Nodal status pN0-2 & $1.424(1.070-1.895)$ & 0.015 \\
Histological grading G1-3 & $0.846(0.446-1.604)$ & 0.608 \\
L1 positive vs L1 negative & $1.771(1.076-2.917)$ & 0.025 \\
Tumor-specific survival & & \\
Tumor invasion depth pT1-4 & $2.375(1.398-4.035)$ & 0.001 \\
Nodal status pN0-2 & $1.630(1.145-2.320)$ & 0.007 \\
Histological grading G1-3 & $1.101(0.539-2.249)$ & 0.791 \\
L1 positive vs L1 negative & $2.638(1.493-4.661)$ & 0.001 \\
\end{tabular}

CI, confidence interval; RR, risk ratio.

overall and tumor-specific survival in a KaplanMeier analysis $(P<0.05$; data not shown). We used Fisher's test to compare bone marrow micrometastasis with and without L1 expression in the primary tumor and found a statistically significant positive association between L1-positive expression of colorectal cancer cells in the primary tumor and the presence of colorectal tumor cells in the bone marrow $(P=0.021) ; 10(56 \%)$ of 18 patients with micrometastatic tumor cells in their bone marrow expressed L1 in their primary tumor (Table 3). Among 64 patients without micrometastatic tumor cells in the bone marrow, $16(25 \%)$ patients had L1-positive tumors.

Lymph nodes were examined immediately after surgical removal. Histopathologically tumor-free lymph nodes were sectioned and stained for disseminated tumor cells with Ber-EP4 monoclonal antibody against epithelial cell adhesion molecule; $41(32 \%)$ of 127 patients had disseminated tumor cells in the lymph nodes (Table 3). Lymph node microinvolvement was strongly and negatively associated with overall and tumor-specific survival in a Kaplan-Meier analysis and log-rank test $(P<0.05$; data not shown). We used a Fisher's test to compare lymph node microinvolvement with L1 expression in the primary tumor (Table 3 ). We found a statistically significant association between L1 expression and lymph node microinvolvement with L1 expression $(P=0.006)$. Primary tumors from 16 $(39 \%)$ of 41 patients with lymph node involvement also expressed L1. Among 86 patients without lymph node microinvolvement, $13(15 \%)$ primary tumor samples were L1-positive.

\section{Discussion}

In an attempt to identify new therapeutic target molecules for colorectal cancer, we determined L1 expression in a subset of $13 \%$ of primary colorectal tumors in a sufficiently large collective of 375 patients. L1 was significantly correlated with bad outcome of patients and also with early micrometa-
Table 3 Association between L1 expression, lymph node and bone marrow micrometastasis status in colorectal carcinoma

\begin{tabular}{|c|c|c|c|c|}
\hline Variable & Total & L1 negative & L1 positive & $\mathrm{P}$-values \\
\hline \multicolumn{5}{|c|}{ Lymph node micrometastasis $(n=127)$} \\
\hline Negative & 86 & 73 & 13 & \\
\hline Positive & 41 & 25 & 16 & 0.006 \\
\hline \multicolumn{5}{|c|}{ Bone marrow micrometastasis $(n=82)$} \\
\hline Negative & 56 & 48 & 16 & \\
\hline Positive & 26 & 8 & 10 & 0.017 \\
\hline
\end{tabular}

Data are presented in cross tables. $P$-values were determined by using two-sided Fisher's tests.

static spread to lymph nodes and bone marrow. While high-quality antibodies are often lacking for genes identified as potential tumor target candidates, L1 can easily be analyzed by immunohistochemistry on formalin-fixed tissues like a tissue microarray. A recent study by Gavert et $a l^{2}$ showed L1 to be expressed at the invasive front of colorectal cancer cells and therefore proposed it as an important factor for metastatic spread and tumor progression. Fitting to this concept, the present study indicates a role of L1 in early micrometastatic spread and shows that L1 can serve as a prognostic marker.

Previous studies described expression of L1 in different tumors of neural crest origin, such as melanomas, gastrointestinal stromal tumors and neuroendocrine tumors of the pancreas and skin. ${ }^{15,35-37}$ On the other hand, epithelial pancreatic adenocarcinomas rarely express L $1 .{ }^{38}$ However, L1 expression is consistently associated with aggressive clinical behavior in other epithelial tumors like uterine, ovarian or also colon carcinomas. $^{2,21}$ The present study shows that the adhesion molecule L1 is upregulated in colorectal cancer specimens and associated not only with bad outcome of patients but also with microdissemination of tumor cells to distant sites, such as lymph nodes and bone marrow. Given that L1 expressed by tumor cells interacts with multiple vascular or platelet integrins, L1 could play an important role in extravasation of tumor cells during early metastatic spread. As mentioned above, L1 is expressed at the invasive front of colon cancer tumors. ${ }^{2}$ Expression of L1 was also described in tumor vessels in renal cell carcinomas and smooth muscle tumors and could therefore enhance attachment of tumor cells by homophilic binding. ${ }^{20,36} \mathrm{~A}$ role of L1 in homing of colorectal cancer cells to lymph nodes and bone marrow is probable, especially since L1 undergoing homophilic binding is also expressed in a subset of lymph node leukocytes. ${ }^{39}$ However, a correlation does not prove a direct role of L1 in this process. Double staining of micrometastatic tumor cells should be performed in future experiments to show coexpression of L1 and epithelial markers in single disseminated tumor cells. Finally, a causal relation- 
ship needs to be examined by functional experiments in in vitro or in vivo models.

In colorectal cancer, the presence of micrometastatic tumor cells in lymph nodes and bone marrow is associated with poor survival. ${ }^{25-27}$ Although the presence of micrometastatic cells in regional lymph nodes is not surprising, colorectal cancer cells are also frequently found in the bone marrow, in contrast to the rather infrequent rate of overt skeletal metastases of colorectal cancer generally observed. Disseminated tumor cells homing to the bone marrow may enter circulation again and migrate to other organs, such as liver or lung, in which better growth conditions for colorectal cancer cells might exist and colorectal cancer metastasis usually occurs. ${ }^{40}$ Pierga et $a l^{33}$ suggested that circulating tumor cells in the peripheral blood that find their way to the bone marrow and survive there appear to have an increased ability to develop into overt metastases. Our results suggest a potential role of L1 in the preferential formation of micrometastases at these sites in colorectal carcinoma.

A recent study clearly showed the feasibility of combining L1-directed growth inhibition and Copper-67 radioimmunotherapy, thereby increasing the efficiency of antibody treatment of metastatic ovarian carcinoma in a mouse model. ${ }^{41}$ Such treatment might also be a potential biological therapy option for colorectal cancer patients who express L1 in the primary tumor. Furthermore, since a metalloproteinase $(A D A M 10)$ cleaves L1 from the tumor cell surface and soluble L1 is detected in the serum of tumor patients, an additional diagnostic tool for colorectal cancer patients is available. ${ }^{21}$

In summary, our results indicate a role for L1 in early micrometastatic spread and show that L1 serves as a powerful prognostic marker for colorectal cancer patients.

\section{Acknowledgement}

We thank the patients who willingly and generously provided data and samples for research purposes. Financial support for this study was provided by a research grant from the Hamburger Stiftung zur Foerderung der Krebsbekaempfung (JTK). We thank Sabine Timmermann for her technical participation in the experiments.

\section{Conflict of interest}

No conflict of interest exists.

\section{References}

1 Boo YJ, Park JM, Kim J, et al. L1 expression as a marker for poor prognosis, tumor progression, and short survival in patients with colorectal cancer. Ann Surg Oncol 2007;14:1703-1711.
2 Gavert N, Conacci-Sorrell M, Gast D, et al. L1, a novel target of beta-catenin signaling, transforms cells and is expressed at the invasive front of colon cancers. J Cell Biol 2005;168:633-642.

3 Brummendorf T, Kenwrick S, Rathjen FG. Neural cell recognition molecule L1: from cell biology to human hereditary brain malformations. Curr Opin Neurobiol 1998;8:87-97.

4 Hortsch M. The L1 family of neural cell adhesion molecules: old proteins performing new tricks. Neuron 1996;17:587-593.

5 Ohnishi T, Matsumura H, Izumoto S, et al. A novel model of glioma cell invasion using organotypic brain slice culture. Cancer Res 1998;58:2935-2940.

6 Schachner M. Neural recognition molecules and synaptic plasticity. Curr Opin Cell Biol 1997;9:627-634.

7 De Angelis E, MacFarlane J, Du JS, et al. Pathological missense mutations of neural cell adhesion molecule L1 affect homophilic and heterophilic binding activities. EMBO J 1999;18:4744-4753.

8 Oleszewski M, Beer S, Katich S, et al. Integrin and neurocan binding to L1 involves distinct Ig domains. J Biol Chem 1999;274:24602-24610.

9 Fogel M, Mechtersheimer S, Huszar M, et al. L1 adhesion molecule (CD 171) in development and progression of human malignant melanoma. Cancer Lett 2003;189:237-247.

10 Gil OD, Sakurai T, Bradley AE, et al. Ankyrin binding mediates L1CAM interactions with static components of the cytoskeleton and inhibits retrograde movement of L1CAM on the cell surface. J Cell Biol 2003;162: 719-730.

11 Gutwein P, Mechtersheimer S, Riedle S, et al. ADAM10-mediated cleavage of L1 adhesion molecule at the cell surface and in released membrane vesicles. FASEB J 2003;17:292-294.

12 Kowitz A, Kadmon G, Verschueren H, et al. Expression of L1 cell adhesion molecule is associated with lymphoma growth and metastasis. Clin Exp Metastasis 1993;11:419-429.

13 Linnemann D, Raz A, Bock E. Differential expression of cell adhesion molecules in variants of K1735 melanoma cells differing in metastatic capacity. Int J Cancer 1989;43:709-712.

14 Miyahara R, Tanaka F, Nakagawa T, et al. Expression of neural cell adhesion molecules (polysialylated form of neural cell adhesion molecule and L1-cell adhesion molecule) on resected small cell lung cancer specimens: in relation to proliferation state. J Surg Oncol 2001;77:49-54.

15 Thies A, Schachner M, Moll I, et al. Overexpression of the cell adhesion molecule L1 is associated with metastasis in cutaneous malignant melanoma. Eur J Cancer 2002;38:1708-1716.

16 Gutwein P, Oleszewski M, Mechtersheimer S, et al. Role of Src kinases in the ADAM-mediated release of L1 adhesion molecule from human tumor cells. J Biol Chem 2000;275:15490-15497.

17 Kalus I, Schnegelsberg B, Seidah NG, et al. The proprotein convertase PC5A and a metalloprotease are involved in the proteolytic processing of the neural adhesion molecule L1. J Biol Chem 2003;278: 10381-10388.

18 Mechtersheimer S, Gutwein P, Agmon-Levin N, et al. Ectodomain shedding of L1 adhesion molecule promotes cell migration by autocrine binding to integrins. J Cell Biol 2001;155:661-673. 
19 Montgomery AM, Becker JC, Siu CH, et al. Human neural cell adhesion molecule L1 and rat homologue NILE are ligands for integrin alpha v beta 3. J Cell Biol 1996;132:475-485.

20 Allory Y, Matsuoka Y, Bazille C, et al. The L1 cell adhesion molecule is induced in renal cancer cells and correlates with metastasis in clear cell carcinomas. Clin Cancer Res 2005;11:1190-1197.

21 Fogel M, Gutwein P, Mechtersheimer S, et al. L1 expression as a predictor of progression and survival in patients with uterine and ovarian carcinomas. Lancet 2003;362:869-875.

22 Pantel K, Brakenhoff RH. Dissecting the metastatic cascade. Nat Rev Cancer 2004;4:448-456.

23 Lugo TG, Braun S, Cote RJ, et al. Detection and measurement of occult disease for the prognosis of solid tumors. J Clin Oncol 2003;21:2609-2615.

24 Greenson JK, Isenhart CE, Rice R, et al. Identification of occult micrometastases in pericolic lymph nodes of Duke's B colorectal cancer patients using monoclonal antibodies against cytokeratin and CC49. Correlation with long-term survival. Cancer 1994;73:563-569.

25 Liefers GJ, Cleton-Jansen AM, van de Velde CJ, et al. Micrometastases and survival in stage II colorectal cancer. N Engl J Med 1998;339:223-228.

26 Yasuda K, Adachi Y, Shiraishi N, et al. Pattern of lymph node micrometastasis and prognosis of patients with colorectal cancer. Ann Surg Oncol 2001;8:300-304.

27 Lindemann F, Schlimok G, Dirschedl P, et al. Prognostic significance of micrometastatic tumour cells in bone marrow of colorectal cancer patients. Lancet 1992;340:685-689.

28 Wittekind C, Greene FL, Hutter RVP, et al. TNM Atlas: Illustrated Guide to The TNM/pTNM Classification of Malignant Tumours, 5th edn. Springer: New York, NY, 2005.

29 Schraml P, Kononen J, Bubendorf L, et al. Tissue microarrays for gene amplification surveys in many different tumor types. Clin Cancer Res 1999;5:1966-1975.

30 Braun S, Vogl FD, Naume B, et al. A pooled analysis of bone marrow micrometastasis in breast cancer. N Engl J Med 2005;353:793-802.

31 Izbicki JR, Hosch SB, Pichlmeier U, et al. Prognostic value of immunohistochemically identifiable tumor cells in lymph nodes of patients with completely resected esophageal cancer. N Engl J Med 1997;337: 1188-1194.

32 Kaifi JT, Yekebas EF, Schurr P, et al. Tumor-cell homing to lymph nodes and bone marrow and CXCR4 expression in esophageal cancer. J Natl Cancer Inst 2005;97:1840-1847.

33 Pierga JY, Bonneton C, Vincent-Salomon A, et al. Clinical significance of immunocytochemical detection of tumor cells using digital microscopy in peripheral blood and bone marrow of breast cancer patients. Clin Cancer Res 2004;10:1392-1400.

34 Latza U, Niedobitek G, Schwarting R, et al. Ber-EP4: new monoclonal antibody which distinguishes epithelia from mesothelial. J Clin Pathol 1990;43:213-219.

35 Deichmann M, Kurzen H, Egner U, et al. Adhesion molecules CD171 (L1CAM) and CD24 are expressed by primary neuroendocrine carcinomas of the skin (Merkel cell carcinomas). J Cutan Pathol 2003;30:363-368.

36 Kaifi JT, Strelow A, Schurr PG, et al. L1 (CD171) is highly expressed in gastrointestinal stromal tumors. Mod Pathol 2006;19:399-406.

37 Kaifi JT, Zinnkann U, Yekebas EF, et al. L1 is a potential marker for poorly-differentiated pancreatic neuroendocrine carcinoma. World J Gastroenterol 2006;12:94-98.

38 Kaifi JT, Heidtmann S, Schurr PG, et al. Absence of L1 in pancreatic masses distinguishes adenocarcinomas from poorly differentiated neuroendocrine carcinomas. Anticancer Res 2006;26:1167-1170.

39 Kowitz A, Kadmon G, Eckert M, et al. Expression and function of the neural cell adhesion molecule L1 in mouse leukocytes. Eur J Immunol 1992;22: 1199-1205.

40 Heiss MM, Allgayer H, Gruetzner KU, et al. Individual development and uPA-receptor expression of disseminated tumour cells in bone marrow: a reference to early systemic disease in solid cancer. Nat Med 1995;1: 1035-1039.

41 Knogler K, Grunberg J, Zimmermann K, et al. Copper67 radioimmunotherapy and growth inhibition by antiL1-cell adhesion molecule monoclonal antibodies in a therapy model of ovarian cancer metastasis. Clin Cancer Res 2007;13:603-611. 